\title{
La puerta de Anuwampar. Literatura oral, paisaje y ritualidad en el Altiplano aymara
}

\author{
Anuwampar Gate. \\ Oral Literature, Landscape and Ritual at The Aymara Altiplano
}

\author{
Gerardo FERNÁNDEZ JUÁREZ \\ (Universidad de Castilla-La Mancha) \\ Gerardo.FJuarez@uclm.es \\ ORCID ID: 0000-0001-5129-4473
}

\begin{abstract}
The Orqorani hill, that watches over people's ceremonial life at Qorpa community in the Bolivian Highlands, has a peculiar geomorphology of intricate rock formations, loaded with myths, traditions and allusions to the local memory, and inscribed in the cognitive map of its structures. This work analyses one of these stone representations which, as an ideogram, displays the story of Anuwampar and becomes a symbolic testimony to the 'Temple's Gate', where within the hill - he is locked. The character's name, Anuwampar - meaning 'dog hand'alludes to his imminent shame and dishonor, linked to his ill-fated and ritualistic entrance to the Achachila hills. This rules the fertility in and outside the hill. This offence by Anuwampar, who forgets his ritual obligations towards Orqorani, makes his state of offeror and donor turn into a symbolic sacrificial offering.
\end{abstract}

KEYWORDS: Aymara, Orqorani, oral PALABRAS-ClAVE: Aymara, Orqorani, literature, lanscape, ritual.
RESUMEN. El cerro Orqorani que tutela la vida ceremonial de los comuneros aymaras de la comunidad de Qorpa, en el Altiplano de Bolivia, ofrece entre sus recovecos geomorfológicos unas estructuras pétreas caprichosas cargadas de relatos, tradiciones y alusiones a la memoria local que aparece inscrita en el mapa cognitivo de sus estructuras. El artículo trata de una de estas representaciones pétreas que, a manera de ideograma, introduce el relato de Anuwampar y constituye el testimonio simbólico de la Puerta del Templo donde se encuentra encerrado en el interior del cerro. Anuwampar, «mano de perro», esconde en su propia denominación, la certeza del deshonor, una falta de correspondencia en el tratamiento ritual con los cerros achachilas, dueños de la fertilidad interna y externa del cerro a quienes pertenece.

literatura oral, paisaje, ritual.

Gracias a las fuentes coloniales y a la documentación arqueológica conocemos el valor ceremonial que los cerros han poseído de larga tradición en las culturas andinas. Incluso las representaciones iconográficas de algunas fuentes coloniales y cerámicas o textiles prehispánicos sugieren la importancia ritual de los cerros en las antiguas culturas de los Andes. Esto no resulta novedad alguna, prácticamente la mayor parte de las monografías antropológicas y etnográficas contemporáneas sobre las actuales sociedades andinas, recogen la relevancia de este hecho (Gil García y Fernández Juárez, 2008: 105). Las montañas y cerros sagrados de los Andes conocidos como apus, machulas, wamanis 
en quechua y mallkus o achachilas en aymara consituyen una variada jerarquía de atributos rituales y ceremoniales, muy en especial el conocido como mallku marani, autoridad anual entre todos ellos que concentra las principales menciones en las correspondientes rogativas ceremoniales, vinculadas con el ciclo productivo en relación con la lluvia, la salud y la convivencia en las comunidades del Altiplano ${ }^{1}$.

Los achachila son los protectores genéricos de las comunidades aymaras. Presentan una indudable heterogeneidad entre sí. Los más señalados, importantes y prestigiosos, que suelen estar presentes en la mayor parte de las letanías y ofrecimientos ceremoniales, son los cerros nevados de la Cordillera Real Andina (Cordillera Oriental), Illimani, Illampu, Wayna Potosí..., incluso el Mururata al que se atribuye especial protección sobre los rateros y delincuentes en algunas versiones ${ }^{2}$. Además de estos grandes nevados, con alturas superiores a los 5.000 metros, conocidos de manera extensa y tenidos en cuenta en la mayor parte de las letanías ceremoniales, incluso en lugares apartados del Altiplano desde donde no se pueden apreciar sus formas, existen otros achachilas aparentemente más modestos, pero que protagonizan la vida social y ceremonial de las comunidades a las que protegen. Cada comunidad sabe cuál es su achachila de referencia, su «abuelo» ${ }^{3}$, a quien debe dirigir sus rogativas y solicitudes en función de los conflictos y necesidades que haya que atender y tratar en cada caso.

Determinados cerros suponen hoy en las sociedades aymaras contemporáneas referentes de pertenencia e identidad local, cuando no lugares de específico ofertorio ceremonial o de iniciación ritual de los propios especialistas caso de los yatiris o ch 'amaqanis (Véricourt, 1999: 45; Fernández Juárez, 2004: 26; Fernández Juárez y Albó Corrons, 2008: 240).

Yatiri es el «Sabio», especialista ritual en el diagnóstico y pronóstico con las hojas de coca, conocedor de herbolaria tradicional y mediador en rituales productivos,

${ }^{1}$ El cerro característico que engalana la mayor parte de las postales de la ciudad de La Paz en Bolivia, recibe la denominación de Illimani, que parece proceder de Illa Umani, «el dueño del agua», como acreditan las frecuentes coronas de nubes que cubren sus cumbres nevadas. Los pobladores aymaras de la zona del lago Titicaca conocen con exactitud sorprendente los vientos que traerán agua y que sortearán la barrera del Illimani y las cumbres de la Cordillera Real andina, de aquellos otros que no. Constituyen «señaleros» que advierten de las características del ciclo productivo que se viene desde las labores iniciales de la roturación de los terrenos de cultivo (Kessel y Enríquez, 2002: 55).

${ }^{2}$ El relato de amor entre Illampu e Illimani y el enojo de Mururata celoso de Illimani que quiso levantarse por encima de ellos. El Inca reaccionó golpeándolo con su onda, de ahí el nombre de Mururata... «desconchado». La adecuación de los cerros a relatos míticos del pasado y circunstancias ceremoniales del presente más rabioso reflejan la gran versatilidad del modelo ceremonial aymara y andino y por supuesto la capacidad adaptativa de los diferentes actores presentes en su sistema de creencias. La antropóloga italiana Francesca Cerbini mostró de una forma etnográfica impecable, la vigencia adaptativa de cerros ceremoniales y ofrendas originarias del dominio rural altiplánico en un contexto tan específico, para los inmigrantes aymaras, como el panóptico de San Pedro en la ciudad de La Paz (Cerbini, 2010: 15). Para una visión sobre los modelos rituales adaptativos aymaras al ámbito urbano, ver Albó, Greaves, Sandoval (1983: 225) y Burman (2011: 120). Igualmente en contexto evangélico el trabajo de Stróbele (1989: 93).

${ }^{3}$ Achachila, viene de achachi, «viejo», «abuelo», circunstancia que aparece fortalecida en los relatos de la literatura oral, en los mitos y en los cuentos protagonizados por ellos, en los que suelen aparecer bajo la forma de un abuelo canoso de poncho blanco. Las cumbres de los principales achachilas se dicen que son sagradas e imposible acceder a su cumbre. Son muy frecuentes los relatos en los que los achachilas levantan ventiscas o confunden a los que se acercan por sus inmediaciones con figuras que generan fascinación como los «toros dorados» cuya intención es perder la orientación y el juicio del inconsciente aventurero (Berg, 1989: 125; Morote Best, 1988: 48). Los achachilas suelen protagonizar los sueños de iniciación de los especialistas en ritual ya sea bajo la forma de borracho, anciano o «gringo» que reclama ser invitado y homenajeado con libaciones y ofrendas, lo que constituye uno de los motivos para acceder a la condición de especialista en ritual, yatiri. La figura del achachila como «gringo» parece vinculada a las expresiones formales del poder político y económico. 
conflictos humanos y problemas terapéuticos. Pueden ser hombres o mujeres y su presencia en las comunidades aymaras del Altiplano es muy reconocida. Los sistemas de iniciación de estos especialistas en ritual resultan complejos y muy variados. El más característico en la region altiplánica cerca del Lago Titica es la elección por el rayo. El rayo constituye desde antiguo, como reflejan algunas cónicas coloniales, el principal agente seleccionador de especialistas rituales con golpes certeros que, según explican los pobladores aymaras, descuartizan al infortunado para retornarle de nuevo a la vida con la posibilidad de iniciarse como yatiri. El rayo suele dejar sus regalos en el lugar en donde se ha producido el encuentro, de tal forma que el candidato a yatiri los encuentra en cuanto retorna a la consciencia. Entre ellos destacan las «gloria bala» o piedras del rayo. En otras ocasiones el rayo marca el cuerpo del aspirante provocándole cicatrices en el cuerpo que el yatiri suele mostrar ante los incrédulos como testimonio irrevocable de la selección de que ha sido objeto. En otras ocasiones el propio cuerpo del candidato a yatiri posee las peculiaridades morfológicas que acreditan su selección ceremonial por parte del rayo, como tener algún órgano corporal duplicado, tener más dedos en manos o pies de lo habitual (sojtillos) o ser ispa, gemelo, cuya naturaleza se atribuye al rayo ${ }^{4}$. Otras formas canónicas reconocidas para aspirar a ser yatiri lo constituyen las enfermedades imprevistas que provocan una gran incapacidad en el infortunado que consigue recuperarse practicando y experimentando en su cuerpo con los remedios tradicionales. Otro cauce para iniciarse como especialista ritual lo establecen los sueños, determinado tipo de sueños. En otras ocasiones la propia presión social es la que propicia la donación de un representante de una parentela concreta de la comunidad para que se inicie como yatiri. Suele ser en casos en los que la comunidad haya perdido a sus yatiris de referencia o se encuentren en una situación de longevidad que impida ya disfrutar de sus servicios. En esos casos la comunidad presionará a aquellas familias que tuvieron yatiris de prestigio en el pasado entre sus familiares para que alguno de sus descendientes se inicie en estos menesteres puesto que de estas familias se dice que «tienen rayo» lo que facilita el acceso como especialistas rituales a su parentela.

Por su parte el ch'amakani, «dueño de la oscuridad y de la fuerza», constituye el especialista ritual de mayor prestigio en las comunidades del Lago Titicaca. Su mayor habilidad consiste en hablar y consultar de viva voz, en consultas a oscuras, habitualmente por la noche, a los cerros, los seres del mundo de abajo y a las entidades anímicas de las personas afectadas en sus consultas, que se personan a su llamado para debatir con él, en voces de diferente textura y tonalidad, sobre los problemas, conflictos y situaciones que aquejan a los que acuden a su presencia (Fernández Juárez, 2004: 40). Encontramos versiones similares en contexto quechua andino en relación a los paqos, papamesayoq y altamisaqoq en las proximidades del Cuzco en Perú (Contreras, 1985:120; Ricard Lanata, 2007: 147; Lorente, 2014: 229). Los modelos de iniciación ceremonial en cada caso otorgan un gran valor a los cerros, lugar en donde suele realizarse. El conocimiento de los más expertos y avezados suele canalizarse a través de los sueños, por indicación específica de los propios achachilas.

De hecho estos «sabios»y «sabias» suelen visitar regularmente los «calvarios» de poder que se encuentran en las laderas y cumbres de los principales achachilas para incrementar su conocimiento ceremonial y conseguir por inferencia, en ocasiones a través

\footnotetext{
${ }^{4}$ El parto gemelar no se considera afortunado en los Andes y suele ser motivo de abandono de uno de los gemelos, especialmente en el caso de hermanos de diferente sexo. En diferentes culturas el parto gemelar se considera algo inapropiado para los seres humanos puesto que solo los animales dan a luz varias criaturas de forma correlativa. En este caso, la duplicación en el seno materno que se achaca al rayo, dota de este poder al gemelo por lo cual, al «tener rayo» puede ser iniciado como maestro ceremonial.
} 
de los sueños, destacadas competencias en sus técnicas diagnósticas y rituales. Los «calvarios» suelen ser conformaciones rocosas de especial significado por su forma o posición, denominadas $w a q^{\prime} a s$ en donde suelen hacerse los sacrificios ceremoniales y que expresan determinados acontecimientos de la memoria local no exenta de componentes de carácter mítico (Astvaldsson, 2000: 47) ${ }^{5}$.

El cerro Orqorani, próximo a la comunidad de Qorpa, y al pueblo de Jesús de Machaqa de la Provincia Ingavi, del Departamento de La Paz (Bolivia), incorpora sobre sus laderas una gran cantidad de rocas enhiestas de formas caprichosas que, como en otros lugares del Altiplano, reciben el apelativo de waq'as y su conjunto la denominación genérica de qalamarka (ciudad de piedra) ${ }^{6}$. Por supuesto, se trata de algo más que piedras inermes, en la tradición local aymara, que ha construido en torno a ellas relatos sobre personajes míticos, espacios simbólicos y recursos a la propia memoria histórica del lugar con sus enfrentamientos y singularidades ${ }^{7}$. Entre ellas cabe destacar la figura de Anuwampar, un líder próspero local que por no respetar las obligaciones rituales con los cerros achachilas, termina preso en su interior como acredita la hornacina que delimita el umbral de entrada al cerro, tal y como puede verse en la actualidad, de cuyo interior, en la hora de los «encantos», emergen perros negros y sonidos maléficos.

Tuve la oportunidad de recorrer las laderas y cumbres del cerro Orqorani de la mano de Hilario durante una de mis estancias en la comunidad de Qorpa, en que me alojé con su familia. A Hilario le encanta contar cuentos, relatos y sucesos de la comunidad, así como pasear por los cerros; es colono en las tierras orientales de San Borja en el Oriente de Bolivia y en cierta ocasión me llevó de paseo al cerro Orqorani, en cuyas proximidades se encuentra su residencia paterna. Su padre es reconocido yatiri en la comunidad y comparte con su hijo el gusto por los relatos legendarios, los seres del Altiplano y la exégesis de los rituales comunitarios. Llama la atención la precisa capacidad de Hilario, habituado al comercio y a los negocios del transporte de mercancías, para interpretar la historia local y las normas éticas de comportamiento de la comunidad a través de las formas caprichosas de las diferentes $w a q^{\prime} a s$ del variopinto paisaje pétreo del cerro Orqorani.

Cada comunidad del Altiplano tiene su propio cerro predilecto al que otorga culto como si fuera de su propia parentela del que se dice «tiene mejor mano» para los comuneros de su jurisdicción. Pese a todo, algunos cerros presentan cierto valor especializado en términos generales pudiendo beneficiar a cualquiera que les tenga fe y realice los sacrificios de la forma estipulada, caso del conocido santuario que configuran las cumbres del cerro Pachjiri en la comunidad de Ajlla (Provincia Omasuyo, del Departamento de La Paz), conocido por su especializada competencia tanto en la distribución de bienes y gracias como justifican los «calvarios», altares o waq'as que adornan sus cumbres y laderas, como en la formación de especialistas rituales o yatiris. El cerro Pachjiri posee además el valor de la ambigüedad ceremonial característica de los altares y «calvarios» del Altiplano, cubriendo los parabienes solicitados por los

\footnotetext{
${ }^{5}$ El valor ceremonial del cerro no solo afecta a su cumbre, sino a toda su superficie rocosa donde es posible reconocer la presencia del achachila. Lo mismo podemos decir de sus adentros. Las interioridades del cerro están salpicadas igualmente de su valor ceremonial como apreciamos en el caso de las minas y el culto al diablo (el tío) (Absi, 2005: 33)

${ }^{6}$ Este término $w a q^{\prime} a$ se aplica a los adoratorios pétreos similares a los del cerro Orqorani como podemos ver para el sector de Jesús de Machaqa, cada uno de ellos con su especificidad ceremonial y su impronta en los relatos míticos y la tradición oral del sector.

${ }^{7}$ La relevancia de las piedras y conformaciones rocosas, en general, formando parte de las tradiciones legendarias andinas así como de los usos rituales cotidianos en las comunidades quechuas y aymaras es algo habitual y conocido (Gutche, 1984: 539).
} 
pobladores en forma de ofrendas ${ }^{8}$, pero dando cabida igualmente a los deseos maléficos y expresiones de aflicciones rituales a través de las ofrendas negras, ch'íyara misa, que son quemadas en el altar apropiado 9 .

Las $w a q^{\prime} a s$ de Orqorani, ofrecen una perspectiva distinta, según el relato de Hilario, dando cabida en primer lugar a un conjunto de referentes del paisaje, algunos con tratamiento ceremonial ${ }^{10}$, que tienen que ver con las necesidades tanto de producción como de reproducción humanas, conceptos formulados y expresados a través de los relatos que las propias piedras y sus emplazamientos en el cerro provocan en alusión a tiempos añejos donde lo histórico y el mito se entrelazan y complementan de forma compleja. El relato se ajusta al paisaje de una forma estrecha donde memoria, oralidad y cultura escrita se dan la mano, si bien, de una forma peculiar, destacando de forma singular el valor de las imágenes inscritas en el paisaje ${ }^{11}$.

Uno de los espacios predilectos de Hilario, por sus connotaciones éticas y morales en clave aymara, es «la puerta del templo de Anuwampar». Algo tan asombroso en su denominación adquiere una forma específica humilde y decepcionante, si lo vemos con ojos occidentales, pues tan solo se muestra como una leve oquedad, apenas una hornacina constituida por un fallo geológico, en forma de «puerta», el resto de la construcción adquiere forma simbólica y ritual «a su hora», en la hora de los «encantos» ${ }^{12}$, a la media noche o en la hora de tránsito entre la noche y el día marcado por la aurora, que propicia encuentros generalmente desagradables en el Altiplano con los malignos seres saxra que se adueñan de la noche, afectando a la salud de quienes tienen la desdicha de tropezárselos.

Debo indicar que el hallazgo del relato que a continuación voy a exponer en palabras de Hilario, fue verdaderamente fortuito, recorriendo las peñas, campas y cárcavas del cerro Orqorani, en un momento en que mis preocupaciones teóricas en antropología versaban sobre las relaciones interculturales en el ámbito de la salud y de las prácticas médicas aymaras (Fernández Juárez, 1999).

Voy a presentar el relato de Hilario extractado de mi cuaderno de campo, para

\footnotetext{
${ }^{8}$ Las ofrendas rituales reciben diferentes denominaciones como mesa, waxt'a (regalo), q'uwacha en contexto urbano, y suelen estar configuradas por hojas de coca, unto y grasas de diferentes especies animales como la llama, la alpaca, el conejo, el cerdo, la gallina o la oveja, en función del cariz de la ofrenda, plantas aromáticas, resinas como el copal o el incienso, azúcar, flores, semillas, frutos y fetos de diferentes especies. El conjunto, elaborado según un orden específico en el que se alternan letanías y alocuciones variadas, es quemado en el lugar donde indica el especialista ritual, previa consulta a las hojas de coca.

${ }^{9}$ El caso del cerro Pachjiri dispone de una $w a q^{\prime} a$ específica para maldiciones, conocida como «Muerte Calvario» (Fernández Juárez y Albó Corróns, 2008: 243; Burman, 2011: 220). De todas formas, existen recursos varios conocidos por los especialistas rituales para hacer los sacrificios dañinos, como colocar las ofrendas negras a la espalda del cerro o en dirección a la puesta del sol y otros varios (Rösing, 2008a: 230; 2008b: 135).

${ }^{10}$ Resaltaba Hilario la renovada reutilización ceremonial de alguno de las $w a q^{\prime} a$ del cerro. Lo mismo podemos indicar con respecto a algunos monolitos tihuanacotas que se encuentran en las comunidades de alrededor.

${ }^{11}$ Cada vez surgen nuevas investigaciones que resaltan la importancia de la imagen y los ideogramas en los relatos andinos analizando la expresividad de formas escriturales no alfabéticas sobre diferentes soportes como textiles, cueros de oveja y llama o estructuras circulares de barro, conocidas como llut'asqas y las waxt'as u ofrendas rituales (Arnold, 2015: 31; Garcés, 2016: 115; 2017: 43; Fernández Juárez, 2018: 31).

${ }^{12}$ El concepto de «encanto» altera las condiciones espacio temporales de las comunidades aymaras. Los lugares que «tienen encanto» son susceptibles de presenciar la aparición de seres fabulosos del pasado, las representaciones sensibles de las entidades tutelares del Altiplano, vislumbrar ciudades escondidas, encontrar tapados, sufrir el ataque aflictivo de seres de la noche..., etc.
} 
realizar luego un breve comentario general sobre su contenido. En cualquier caso he utilizado de forma exhaustiva y en extenso las notas a pie de página para explicar de forma adecuada los términos o conceptos que, entiendo, son precisos aclarar para que el relato sea comprensible.

\section{EL RELATO: EL TEMPLO DE ANUWAMPAR ${ }^{13}$}

Esta es la puerta del templo ${ }^{14}$. Este tiene una historia. En tiempos remotos, los abuelos cuentan de que donde yo vivía, donde mi casa, era una parcela de una persona que era más rica. Y esa persona se llamaba Anuwampar. Y ese tenía dice que bastante ganado, como llamas, ipor miles!, alpacas y tenía bastante ganado y tenía un criado. Ese criado se encargaba de cuidar todo ese ganado, dice. Pero él, creo que se atenía a los achachilas ${ }^{15}$ y ese achachila es una persona cualquiera, pero de temer ¿no? Pero un día él se olvidó de dar su sacrificio a los achachilas, el Anuwampar ${ }^{16}$. ¿Qué ha pasado? El Anuwampar, una noche ha caído en manos de los achachilas. De aquí dicen que bajaron esos vestidos de oro ¡morenos! $!^{17}$ montados en caballo, de oro pero eran esos. A media noche justo estaba durmiendo el Anuwampar. Se lo llevaron al Anuwampar y se lo han traído aquí dicen, pero su criado ha venido, ha seguido de atrás, y lo han dejado por ahí abajo y esta puerta estaba una buena, ¡buena ciudad!, dice que se abría un tiempo, se abría y de oro ahí

${ }^{13}$ Anuwampar (Anu ampara) «mano de perro», humanizando lingüísticamente al personaje. Agradezco a los lingüistas Julio Calvo Pérez de la Universidad de Valencia y a Xavier Albó Corrons de CIPCA, La Paz, sus apreciaciones sobre el término aymara que identifica al personaje. A ellos debo la grafía más correcta del término que en el relato recogido oralmente se expresaba como «anuampa».

${ }^{14}$ Se trata de una oquedad en la roca que tiene forma de hornacina.

${ }^{15}$ Anuwampar, tiene en cuenta a los achachilas y les atiende según la costumbre ceremonial.

${ }^{16}$ Existe la costumbre de pagar ceremonialmente a los cerros y a la pachamama, la víspera del primero de agosto mediante ofrendas complejas (Fernández Juárez, 1996: 205). La reacción furibunda de los cerros parece desproporcionada pero ejemplarizante en el seno de la comunidad.

${ }^{17}$ Se refiere a los miembros de la comparsa de morenada. Los gringos en esta narración persiguen a Anuwampar en sus caballos de oro, vestidos de «moreno». Los caballos de oro y la situación descrita alude al oro vivo del Anchanchu, personaje saxra, maligno, que habita las cárcavas y quebradas solitarias de los cerros (Fernández Juárez, 2008: 124-125). El oro vivo aparece en diferentes momentos del año como la víspera del primero de agosto o durante la fiesta de la Cruz en Mayo. las irisaciones azuladas marcan el sitio en el que se encuentra en la forma de animales diminutos de oro con movilidad completa. Al desplazarse producen esas fulguraciones azuladas, rojas y blancas. El que consigue capturarlos ganará fortuna y riqueza para toda la vida, para ello debe marcar una cruz con un cuchillo en el lugar de donde emanan los irisaciones azuladas y orinar en esa dirección al tiempo que se corta el aire con el cuchillo mientras se hace la señal de la cruz (Spedding, 1992: 299). Si no se hace de forma adecuada este pequeño ritual al excavar en el interior de la tierra, en lugar del «oro vivo» solo se encontrará una olla vieja repleta de sapos porque el «oro vivo» habrá escapado hacia el interior del cerro. Este oro presenta las atribuciones características del tiempo antiguo, el tiempo de los chullpas, los ñawpas o el tiempo del Inca. El proceder del anchanchu tiene que ver con el pasado; las personas que quedan bajo su tutela, pierden el juicio, las mujeres son violadas con su gran miembro y su ajayu (alma principal) es capturado en el interior de la montaña, como le ha sucedido a Anuwampar por su negligente proceder al olvidarse de cumplir el pago a los achachilas. Los personajes capturados por los cerros se caracterizan entre otras cosas por la adopción de lenguas antiguas y vestidos añejos que los hacen irreconocible cuando retornan ocasionalmente a sus comunidades con el juicio turbado (Neila Boyer, 2006: 187; Polia Meconi, 1996: 250). En este caso, su permanencia en el interior del cerro, ya sea en cuerpo o a través de la captura de alguna de sus ch 'iwis, «sombras», emparenta al afligido con los seres del pasado, los antiguos chullpas, de ahí la ropa que visten y las lenguas antiguas que hablan. No faltan tradiciones similares sobre la captura de personas y su prisión en el interior del cerro en los Andes ecuatorianos según la tradición de la mama huaca (Gutiérrez Estévez 1988: 225). El ser capturado por los cerros y huacas también presenta sus manifestaciones en los relatos coloniales y de extirpación de idolatrías, en ocasiones compatible con la dolencia del susto o con la propia iniciación ceremonial de los afectados (Sánchez, 1991: 125; Fernández Juárez, 2012: 45). 
adentro $^{18}$. Pero al criado lo han botado ahí, lo han dejado ahí no más, al Anuwampar lo han metido aquí adentro y se ha quedado hasta hoy día, para siempre, está cerrado ahí adentro y sus ganados se han muerto y se han desaparecido así no más. El criado que se ha quedado con ganado, el criado ¡así no más esos ganados! ${ }^{19}$ que habí... llamas... se murieron todos. Ahí se desapareció su historia de ese hombre. Ese significado tiene este templo. Este es natural. Este tiene un, como un «encanto», «encanto» tiene, sí. A su hora tiene encanto ${ }^{20}$, se abre la puerta dice, y en su hora también dice que unos perros, varios perros dice que suenan aquí en este puerta. Si, entonces en su tiempo, en su hora se abre esta puerta; cualquier momento se puede abrir dice, no sabemos, se puede abrirse y a la vez este es poderoso. Si te pides alguna cosita entonces como una virgen ${ }^{21}$ entonces, te pides no más, entonces, tranquilo no más, consigues no más ${ }^{22}$ Venían, venían [la gente de la comunidad], pero ahora está olvidado este «templo». Ya se han olvidado ${ }^{23}$. Anuwampar es nombre originario, antiguo. Tiempo de los incas, ¡antes todavía! ${ }^{24}$ Ya se han olvidado, ya no se recuerdan este, pero un día nosotros venimos a pagar a este lugar, parece que la suerte... ¡ha ido bien no más! De aquí, ha ido bien., hemos pagado aquí...bien ha ido, resulta. Con mesa hemos pagado, entonces con el tiempo va a mejorar ${ }^{25}$. Los abuelos habían visto puerta abierta y de ahí adentro han visto perros ladrando y ruidos no más, perro han escuchado ${ }^{26}$. Sí, morenos de baile, danza. No son gente negra, pero son gringos, pero vestidos de morenos $^{27}$ (Fernández Juárez, 2002: 174-175).

${ }^{18}$ Existen diversas narraciones populares sobre ciudades de oro, ocultas en el interior de los cerros o sumergidas en los lagos de los Andes (Morote Best, 1988: 74).

${ }^{19}$ Los ganados son tomados por los achachilas como pago en desagravio al olvido ceremonial de Anuampa. Una vez más el incumplimiento de las normas rituales provoca la catástrofe tanto en lo que afecta a la producción como al orden social aymara. En la localidad de Qorpa y en la provincia Ingavi, la producción agrícola de tubérculos de altura como la papa y gramíneas como la quinoa, se complementa igualmente con las recuas de llamas y alpacas que constituyen un criterio de reconocimiento y prestigio económico y social en el sector, como reflejan las fuentes antiguas en relación con sus propios caciques y líderes más representativos, como en el caso del relato de Anuwampar (Choque 2003: 86-87).

${ }^{20}$ Esa «hora» invierte la relación espacio tiempo acostumbrada en la esfera cotidiana, de tal forma que son frecuentes y posibles los encuentros con los seres tutelares, los malignos y los del pasado.

${ }^{21} \mathrm{La}$ «puerta» tiene forma de hornacina como si fuera el soporte espacial de una imagen religiosa. Por otra parte observamos la enorme facilidad de Hilario para integrar en su discurso, sin contradicción aparente, los referentes populares aymaras y los cristianos.

${ }^{22}$ El lugar participa del sentido de «deuda de ofrenda» que los sacrificios de las mesas suponen en el Altiplano, como refleja (Rösing, 1994: 191).

${ }^{23} \mathrm{El}$ olvido de las formas rituales tradicionales, de las «costumbres» constituye un reclamo persistente de los mayores con respecto a las jóvenes generaciones aymaras. Ante cualquier tipo de adversidad, ya sea en la producción de los campos, recuas ganaderas o en la salud, no es extraño que alguien reclame este tipo de olvidos. Las costumbres rituales pretenden, entre otros motivos, garantizar simbólicamente y canalizar adecuadamente las necesidades humanas de los pobladores. Cuando surgen los inconvenientes, alguna voz reclama este tipo de olvidos, incluso entre los jóvenes.

${ }^{24}$ La referencia a los incas es un marcador temporal muy frecuente en las sociedades andinas; se emplea, más allá de la correcta adscripción incaica del objeto o del hecho que se narra, con el pasado y lo antiguo.

${ }^{25}$ Es muy interesante la observación de Hilario sobre la búsqueda de nuevos referentes ceremoniales que resulten exitosos en el complejo espacial del cerro.

${ }^{26}$ Los perros ofrecen una tipología de representaciones muy significativas en el Altiplano aymara. Soñarse con perros implica que alguien cercano te va a robar. Escuchar perros ladrando en la noche es mal presagio a la hora de hacer ofrendas rituales o curar el mal del «susto». Los perros negros son empleados por los difuntos para cruzar las masas acuosas que separan el mundo de los vivos del de los muertos. Algunos personajes maléficos como los kharisiris pueden adquirir forma de perro o de burro en sus andares por los espacios desolados del Altiplano. Los perros desollados y colocados sobre el cuerpo del enfermo se emplean en el modelo de «muerte cambio» para engañar a la enfermedad al tiempo que el perro se entierra «con el nombre» del enfermo, en el cementerio de la comunidad.

${ }^{27}$ El baile de «morenada», suele danzarse hoy en las comunidades del Lago Titicaca en las principales fiestas patronales. La presencia de comparsas de morenos en estos actos suelen redundar en el prestigio social del preste que lo financia puesto que se trata de comparsas costosas por el número de participantes y 
El relato acentúa la mutua necesidad que en el Altiplano tienen los seres humanos de aquellos seres excepcionales que protegen su entorno. No es una excepción, algo similar sucede en el interior de la mina con la figura del «tío» situación reflejada por Jun Nash (1985) en palabras de los mineros: «nosotros comemos la mina y la mina nos come a nosotros», en justa reciprocidad; o en los términos de la producción agrícola tal y como refleja Hans Van den Berg (1989) en el libro que dio cuenta de su tesis doctoral «La tierra no da así no más». Por tanto la fecundidad de tierras, ganados, cerros y minas de las que depende el mantenimiento de los seres humanos depende de los recursos ceremoniales que han de tenerse en cuenta para con los seres excepcionales de los que depende la vida humana. La manera adecuada es mediar en sus voluntades mediante las correspondientes ofrendas rituales que afectan al desarrollo tanto de los cultivos como de las recuas ganaderas como es el caso en el relato de Anuwampar (Fernández Juárez, 1995: 67; 1997: 102-116; 2012; Ricard Lanata, 2007: 74; Lecoq y Fidel, 2000:149; Tomoeda, 1994:284289).

El problema estriba en el legado que las ofrendas constituyen no solo para los contrayentes (en este caso Anuwampar y los achachilas del cerro) sino incluso para los propios descendientes. Recuerdo un caso que recogí en una comunidad próxima a la localidad de Achacachi (capital de la provincia Omasuyo del Departamento de La Paz), cerca del Lago Titicaca, en donde la enfermedad que presentaba un padre de familia aymara y que lo retenía en casa contra su voluntad con una ostensible cojera, se debía, según el yatiri a la presencia de una ofrenda ritual antigua en el troje del hogar campesino, donde se almacenan los productos de la cosecha. El tratamiento terapéutico implicaba esa deuda de ofrenda que obligaba a actualizar el trato, el convenio o acuerdo sustentado entre la casa, el hogar, la familia y las entidades tutelares que habían recibido la ofrenda. Para ello el yatiri junto con los familiares del enfermo buscaron de forma detenida la ofrenda hasta encontrarla. Posteriormente lo que hizo el yatiri fue actualizar el acuerdo reponiendo los ingredientes de la ofrenda que estaban caducos, muy especialmente los componentes grasos y los «misterios» ${ }^{28}$ y revitalizando el pacto entre los seres tutelares aymaras y la familia, buscando así su protección en la cosecha.

Llama la atención que el especialista ritual no contempló necesidad alguna de intervenir sobre el cuerpo del afectado teniendo en cuenta el origen del mal y su proyección física en el enfermo.

Esta idea del pacto ceremonial con los seres tutelares andinos, que beneficia la economía doméstica de la familia en sus bienes más necesarios como es la cosecha y el ganado, resulta muy frecuente en las poblaciones andinas. De hecho, el ciclo productivo va encaminado en términos rituales a lo largo de todo el periodo. Desde la preparación ritual de los terrenos, aprovechando que la «pachamama hambrea» en torno al primero de agosto, hasta la celebración de la Cruz de Mayo donde se suelen festejar a los productos o incluso en la celebración de San Juan, con el «señalado» del ganado (Fernández Juárez,

por el alquiler del vestuario. Hoy se relacionan con el dominio urbano, amestizado, frente al resto de comparsas autóctonas que ejecutan sus interpretaciones y bailes en las comunidades rurales. Como indica Hilario, se trata de «morenos» especiales puesto que son «gringos» luciendo trajes de oro, motivo propio de las riquezas del cerro y de los seres que lo habitan en su interior, caso del Tío de las minas y de los propios achachilas con los que comparten estos «morenos» idéntica apariencia del «poder», como gringo. Estos «morenos» son los que capturan a Anuwampar y lo llevan al interior del cerro, en esa ciudad de oro que solo se entrevé por la puerta de acceso en la hora de los «encantos».

${ }^{28}$ Los «misterios» constituyen una especie de galleta configurada con azúcar y cal que presenta un diseño en bajorrelieve alusivo al contexto general de la ofrenda (Girault, 1988:35; Berg, 1985: 125; Martínez, 1987: 60). 
2002: 54-99; Ochoa, 1976: 8). Todavía se escucha, incluso entre los adolescentes aymaras que viven en las comunidades rurales, apelar a las ofrendas rituales cuando el año viene malo. Suelen quejarse por el olvido de la tradición, de la «costumbre», como dicen, de hacer el «pago» a la tierra, lo que explica las malas cosechas. Este aspecto constituye el problema de fondo del relato, el olvido de Anuwampar con respecto a los que son sus benefactores rituales, los achachilas, produce como consecuencia el colapso completo de sus bienes, la mortandad de todo su ganado y, finalmente, su clausura en el interior del cerro a través de la «puerta del templo».

Estos portales que permiten transitar entre diferentes dimensiones, en la hora de los «encantos», igualmente son muy frecuentes en la tradición oral andina y en los relatos locales. El propio Julio Verne nos enseñó de una forma explícita cómo en los adentros del mundo (y del cuerpo) suele encontrar acomodo tanto lo antiguo como lo valioso que añoran los humanos y así se narra en diferentes tradiciones amerindias (Gutiérrez Estévez, 2002). En el caso de los relatos andinos con una particularidad: el que permanece mucho tiempo dentro del cerro termina perdiendo la razón y retorna vestido de ropas viejas, como los antiguos, y hablando una lengua primitiva, ininteligible ${ }^{29}$, como he indicado anteriormente. Este tránsito entre el pasado y el presente que la puerta de Anuwampar facilita es remarcado por los perros que la custodian quienes a manera de eficaces psicopompos, conducen las almas de los difuntos sobre sus lomos, cruzando el río que separa el mundo de los vivos del de los muertos, según la tradición aymara. No es el único umbral que podemos identificar en la puerta de Anuampar. En el mundo de abajo y de adentro manqhapacha, de donde surgen los achachilas danzando la «morenada», bajo la forma de autoridad que representan los «gringos» moran los seres malignos, dentro de una cierta ambigüedad moral, conocidos genéricamente como saxras. Son malintencionados, pero tremendamente poderosos, dueños de la riqueza del cerro como es el caso de los minerales preciosos. ${ }^{30}$

La puerta del templo de Anuwampar, no es un caso aislado. Son muchas las waq'as conocidas en el Altiplano aymara, incluso en las proximidades del cerro Orqorani que son objeto de ofrendas y de atenciones rituales, incorporando un relato específico sobre su propia especificidad ritual. Es el caso de la waq’a kasasratqala, donde los pobladores, según Hilario acudían a hacer ofrendas para tener familia, puesto que la gran piedra que la representa parece contener un relieve que semeja un awayu con su criatura a la espalda. Hacían las ofrendas para que naciera más gente en tiempos de los conflictos intercomunitarios por los lindes de terreno que se produjeron en el sector ${ }^{31}$.

La vigencia contemporánea de las $w a q^{\prime} a$ del cerro Orqorani queda de manifiesto por el interés ceremonial que aglutinan en la actualidad, visitados por los Mallkus y

\footnotetext{
${ }^{29}$ Los deseos de los seres del cerro en atrapar a la gente en su interior no solo lo propician los achachilas, sino personajes que frecuentan los cerros caso del anchanchu que hace perder la razón a quien lo escucha, o los chullpa, los seres de la antigüedad vinculados con los restos arqueológicos y las tumbas del pasado, todos ellos comprometen la salud de la gente apoderándose de su ajayu y haciéndoles enfermar de «susto» (Gil García, 2014: 273)

${ }^{30} \mathrm{El}$ mundo aymara aparece distribuido en tres ámbitos diferenciados, el «mundo de arriba», Alaxpacha, donde moran los santos, las vírgenes y los fenómenos meteorológicos como el rayo; «este mundo», Akhapacha, poblado por los seres humanos, los animales y vegetales, pero también los cerros y la tierra y el «mundo de abajo y de adentro», manqhapacha, ocupado por los seres saxra, malignos y los chullpa del pasado.

${ }^{31}$ Hay varios casos recogidos por los testimonios históricos, como los combates por los linderos de tierras entre el Canton de Guaqui y el de Jesús de Machaqa o entre las comunidades de Sullka Titi Titiri y Sullka Titi Lawa Qoyu (Astvaldsson, 2000: 189).
} 
$\mathrm{T}^{\prime}$ allas ${ }^{32}$, autoridades ceremoniales de las comunidades que integran el Cantón con la finalidad de regularizar el ciclo productivo o bien atender las necesidades rituales concretas de las comunidades y familias (Fernández Juárez 2000: 175-178) ${ }^{33}$.

\section{CONCLUSIONES: EL RELATO, LA MEMORIA Y LA PIEDRA}

Dicen los pobladores aymaras de la zona boliviana del Lago Titicaca que soñarse con un perro o con un perro que te lame la mano o te escupe es síntoma de traición, robo, de una decepción emocional profunda, además protagonizada por alguien cercano vinculado a la familia, a los afectos más significativos. Es lo que realiza Anuwampar, «mano de perro», que parece indicar en su propio nombre una felonía anunciada. Su olvido ceremonial, provoca la decepción afectiva de los achachilas, aborta la norma de una deuda de ofrenda exitosa con ellos que precisa su renovación periódica, renovarse sistemáticamente para ser eficaz. Todo esto echa por tierra el descuido de Anuwampar, con las consecuencias terribles que el relato señala. Por si fuera poco el relato aparece situado en un espacio concreto, el cerro Orqorani, donde se plasma a través de los roquedos, diaclasas y fallas que configuran qalamarka, la ciudad de piedra donde afloran mitos y relatos locales entremezclados con la memoria ceremonial y los altares de culto que protegen los achachilas ${ }^{34}$.

El cerro Orqorani constituye un formato específico donde los relatos andinos toman cuerpo y expresión sensible a través de un paisaje cognitivo que configura un relato moral con serias proyecciones contemporáneas en las conductas y procedimientos económicos sociales y ceremoniales de las comunidades aymaras. En cualquier caso, el referente del incumplimiento del vínculo ceremonial que la ofrenda ritual establece entre oferente y destinatario cambia los términos de la relación, convirtiendo a este último en objeto ceremonial y ofrenda humana que el cerro recibe complacida en su interior.

Los sacrificios humanos no adquirieron, hasta donde sabemos, el esplendor en época prehispánica de otras áreas culturales, caso de Mesoamérica con las civilizaciones Maya y Azteca. Sin embargo son numerosos los ejemplos etnográficos actuales que aluden al valor e importancia ritual del sacrificio humano, potenciando otras modalidades sucedáneas mediante las wilanchas de auquénidos o la simulación del canibalismo ritual ${ }^{35}$ (Fernández Juárez, 2015: 157).

Anuwampar, en el interior del cerro, convertido él mismo en icono del pasado, continúa como referente en las nuevas generaciones aymaras del cuidado que los tratos ceremoniales merecen, con los abuelos, los cerros achachilas, que siguen dando sentido a un paisaje donde los relatos se inscriben en ideogramas pétreos que refuerzan la memoria y la manera de ejercer el liderazgo político y ceremonial en el Altiplano. Ahí

${ }^{32}$ Tata Mallku y Mama T'alla son las denominaciones que reciben las autoridades comunitarias del Cantón (Ticona y Albó, 1997: 81-82).

${ }^{33}$ De hecho cabe mencionar que no solo están plenamente vigentes las waq'as del cerro Orqorani en relación con el ciclo productivo cuya obligación reside en las autoridades comunitarias como he indicado sino que también se han reactivado procesos de recuperación ceremonial de monolitos prehispánicos como en el caso de Sullka Titi Titiri. La implicación de las autoridades comunales en el dominio ceremonial aymara está presente en diferentes espacios y dominios, tal y como es el caso del propio Anuwampar, como recoge Rivière (1982; 1995).

${ }^{34}$ Hay que resaltar que no he conseguido localizar ni en los repertorios folclóricos de Efraín Morote Best, ni en las referencias de Antonio Paredes Candia o Mario Montaño Aragón algún relato similar, ni en castellano, quechua o aymara sobre Anuwampar. Tampoco he localizado noticia alguna sobre el relato tras compartirlo con autores como Xavier Albó, Henrique Urbano (+) o Julio Calvo.

${ }^{35}$ El cronista Blas Valera (1992 [1584]) da cuenta de este hecho por la consideración nominal que los auquénidos andinos tenían en los sacrificios humanos a los que se trataba como personas. 
queda la puerta del templo de Anuwampar con sus ladridos y sombras amenazadoras que «a su hora» advierten a los lugareños de su presencia. 


\section{BIBLIOGRAFÍA}

ABSI, Pascale (2005): Los ministros del diablo. El trabajo y sus representaciones en las minas de Potosi, La Paz, IFEA/IRD.

DOI: https://doi.org/10.4000/books.ifea.4003

Albó, Xavier, Greaves, Tomas y SANDOval, Godofredo (1983): Chukiwagu. La cara aymara de La Paz, vol. III. Cabalgando entre dos mundos, La Paz, CIPCA.

ARNOLD, Denise (2015): «Del hilo al laberinto: Replanteado el debate sobre los diseños textiles como escritura», Textualidades. Entre cajones, textiles, cueros, papeles y barro, Fernando Garcés y Walter Sánchez (eds.), (Cochabamba), INIAM-UMSS, pp. 31-54.

ASTVALDSSON, Astvaldur (2000): Las voces de los wak'a. Jesús de Machaqa, la marka rebelde, 4, La Paz, CIPCA.

BERG, Hans van den, (1985): Diccionario religioso aymara, Iquitos, CETA/IDEA.

BERG, Hans van den (1989): La tierra no da así no más. Los ritos agrícolas en la religión de los aymara-cristianos, Amsterdam, CEDLA.

Burman, Anders (2011): Descolonización aymara. Ritualidad y política, La Paz, Plural.

CERBINI, Francesca (2010): La casa de jabón. Etnografía de una cárcel boliviana. Barcelona, Bellaterra.

CONTRERAS, Jesús (1985): Subsistencia, ritual y poder en los Andes, Barcelona, Mitre.

Choque, Roberto (1993): Jesús de Machaqa: la marka rebelde, I. Cinco siglos de Historia, La Paz, Plural / CIPCA.

FERNÁNDEZ JUÁREZ, Gerardo (1995): El banquete aymara. Mesas y yatiris, La Paz, Hisbol.

FERNÁNDEZ JUÁREZ, Gerardo (1997): Entre la repugnancia y la seducción. Ofrendas complejas en los Andes del Sur, Cuzco, Centro de Estudios Regionales Andinos Bartolomé de las Casas.

FERNÁNDEZ JUÁREZ, Gerardo (1996): «El mundo abierto. Agosto y Semana Santa en las celebraciones rituales aymaras», Revista Española de Antropología Americana, 26, pp. 205-229.

FERNÁNDEZ JUÁREZ, Gerardo (1999): Médicos y yatiris. Salud e Interculturalidad en el Altiplano aymara, La Paz, CIPCA

FERNÁNDEZ JUÁREZ, Gerardo (2002): Aymaras de Bolivia. Entre la tradición y el cambio cultural, Quito, Abya-Yala.

FERNÁNDEZ JUÁREZ, Gerardo (2004): Yatiris y ch'amakanis del Altiplano aymara. Sueños, testimonio y prácticas ceremoniales, Quito, Abya-Yala.

FERNÁNDEZ JUÁREZ, Gerardo (2008): «Terrores de agosto. La fascinación del Anchanchu en el Altiplano aymara de Bolivia», Antropologías del miedo. Vampiros, sacamantecas, locos, enterrados vivos y otras pesadillas de la razón, Gerardo Fernández Juárez y Jose Manuel Pedrosa (eds.) (Madrid), Calambur, pp. 119-144.

FERnÁNDEZ JuÁREZ, Gerardo (2012): Hechiceros y Ministros del Diablo. Rituales, prácticas médicas y patrimonio inmaterial en los Andes (Siglos XVI-XXI), Quito, Abya-Yala.

FERNÁNDEZ JUÁREZ, Gerardo (2015): «Diablo y ch’amakani. Antropofagia simbólica y maleficio en el Altiplano aymara de Bolivia», Chungará. Revista de Antropología Chilena, 47, 1, pp. 157-165. 
DOI: https://doi.org/10.4067/S0717-73562015005000006

FERNÁNDEZ JUÁREZ, Gerardo (2018): Humo, barro y cuero. Recorridos de la memoria en los Andes del Sur (Ofrendas y Plegarias), Quito, Abya-Yala.

FERNÁNDEZ JUÁREZ, Gerardo y AlBÓ CORRONS, Xavier (2008): «Pachjiri, cerro sagrado del Titicaca», Revista Española de Antropología Americana, 38 (1) pp. 239-255.

GARCÉS, Fernando (2016): «Inscripciones y escrituras andinas. Un sistema complejo y denso de visualidades, oralidades y espacialidades», Boletín del Museo Chileno de Arte Precolombino, 21, 1, pp. 115-128.

DOI: https://doi.org/10.4067/S0718-68942016000100008

GARCÉS, Fernando (2017): Escrituras andinas de ayer y de hoy, Cochabamba, INIAMMUSS.

GIL GARCÍA, Francisco M. (2014): «Otro mundo adentro de la chullpa. Ruinas arqueológicas, mundos permeables y espacios peligrosos en el Altiplano Sur andino» en, Tiempo, espacio y entidades tutelares, Óscar Muñoz Morán y Francisco M. Gil García (coords.), (Quito), Abya-Yala, pp.273-305.

GIL GARCíA, Francisco M. y FERnÁndeZ JuÁreZ, Gerardo (2008): «Dossier. El culto a los cerros en el Mundo Andino. Estudios de caso», Revista Española de Antropología Americana, 38, 1, pp. 105-113.

GIRAUlt, Luis (1988): Rituales en las regiones andinas de Bolivia y Perú, La Paz, MUSEF/CERES/QUIPUS.

GuTCHE, Maarten VD. (1984): «El ciclo mítico andino de la piedra cansada», Revista Andina, 4, pp. 539-556.

GUTIÉRREZ ESTÉVEZ, Manuel (1988): «Hipótesis y comentarios sobre la significación de la mama huaca», Mito y ritual en América, Manuel Gutiérrez Estévez (comp.), Madrid, Alhambra, pp. 286-323.

GutiÉRreZ EstéveZ, Manuel (2002): «Interioridades», Según Cuerpos. Ensayo de diccionario de uso etnográfico, Manuel Gutiérrez Estévez (ed.), (Badajoz), Cicón Ediciones, pp. 83-141.

KeSSEl, Juan Van y ENRÍQueZ, Porfirio (2002): Señas y señaleros de la madre tierra, Quito, Abya-Yala.

LeCOQ, Patrice y Fidel, SERGIO (2000): «Algunos aspectos de la vida y los ritos ganaderos, una comunidad pastoral del Sud de Potosí», Pastoreo Altoandino. Realidad, sacralidad y posibilidades, Jorge Flores y Yoshiki Kobayashi (eds.), La Paz: PLURAL / MUSEF, pp. 149-187,

LORENTE, David (2014): «El vuelo nocturno de los cerros-pájaro. Ceremonias de llamada a los apus en el Sur del Perú», Tiempo, espacio y entidades tutelares. Etnografías del pasado en América, Óscar Muñoz y Francisco M. Gil García (coords) (Quito), Abya-Yala, pp. 229-272.

MARTÍNEZ, Gabriel (1987): Una mesa ritual en Sucre, La Paz, Hisbol.

Morote Best, Efraín (1988): Aldeas sumergidas, Cuzco, Centro de Estudios Regionales Andinos «Bartolomé de las Casas».

NASH, June (1985): «Religión, rebelión y conciencia de clase en las comunidades mineras», Allpanchis Phuturinqa, 26, pp. 115-135.

NEILA BOYER, Isabel (2006): «El "samay", el susto y el concepto de persona en Ayacucho (Perú)», Salud e Interculturalidad en América Latina. Antropología de la Salud y Crítica Intercultural, Gerardo Fernández Juárez (coord.), (Quito), Abya-Yala, pp. 187-215.

Polia Meconi, Mario (1996): «Despierta, remedio, cuenta....»: Adivinos y médicos del Ande (dos volúmenes), Lima, Pontificia Universidad Católica del Perú. 
RICARD LANATA, Xavier (2007): Ladrones de sombra. El universo religioso de los pastores del Ausangate, Cuzco, IFEA / CERA. DOI: https://doi.org/10.4000/books.ifea.611

RIVIÈRE, Gilles (1982): Sabaya: Structures socio-èconomiques et représentations symboliques dans les Carangas, Bolivie. EHESS, Tesis de Doctorado, París.

RIVIÈRE, Gilles (1995): «Caminos de los muertos, caminos de los vivos: Las figuras del chamanismo en las comunidades aymaras del Altiplano boliviano», Revista de Antropología, 10, pp. 109-132.

RöSING, Ina (1994): «La deuda de ofrenda. Un concepto central de la religión andina», Revista Andina, 12, 1, pp. 191-216.

RösING, Ina (2008a): Defensa y Perdición. La curación negra. Rituales nocturnos de curación en los Andes bolivianos, Madrid, Iberoamericana. DOI: https://doi.org/10.31819/9783964565945

RÖSING, Ina (2008b): Cerrar el círculo. La curación Gris como tránsito entre la negra y la blanca. Rituales nocturnos de curación en los Andes bolivianos, Madrid, Iberoamericana.

DOI: https://doi.org/10.31819/9783964565938

SÁnCHEZ, Ana (1991): Amancebados, hechiceros y rebeldes. Chancay (Siglo XVII), Cuzco, Centro de Estudios Regionales Andinos Bartolomé de las Casas.

SPEDDING, Alisson (1992): "Almas, anchanchos y alaridos en la noche. El paisaje vivificado de un Valle Yungueño», Etnicidad, economía y simbolismo en los Andes, Silvia Arze (Comp.), (La Paz), Hisbol / IFEA / SBH / ASUR, pp. 299-330. DOI: https://doi.org/10.4000/books.ifea.2312

STRÖBELE, Juliana (1989): Indios de piel blanca. Evangelistas fundamentalistas en Chukiawu, La Paz, HISBOL.

TiCONA, Esteban y AlBÓ, Xavier (2000). Jesús de Machaqa: La marka rebelde, 3. La Lucha por el poder comunal, La Paz, CIPCA.

TomoEDA, Hiroyasu (1994): «Los ritos contemporáneos de camélidos y la ceremonia de la citua», El mundo ceremonial andino, Luis Millones y Yosio Onuki (Eds.), (Lima), Horizonte, pp. 283-299.

VALERA, Blas (1992 [1584]): «Relación de las costumbres antiguas de los naturales del Pirú», en, Antigüedades del Perú, Henrique Urbano y Ana Sánchez (eds.), (Madrid), Historia 16, pp. 44-122.

VÉRICOURT, Virginie de (1999): Rituels et Croyances Chamaniques dans les Andes Boliviennes, Paris, L’ Harmatan.

Fecha de recepción: 31 de enero de 2019

Fecha de aceptación: 7 de marzo de 2019

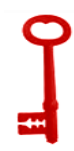

